\title{
Faculty online learning communities: A model for sustained teaching transformation
}

\author{
Melissa Dancy, ${ }^{1}$ Alexandra C. Lau, ${ }^{1, *}$ Andy Rundquist, ${ }^{2}$ and Charles Henderson ${ }^{3}$ \\ ${ }^{1}$ Department of Physics, University of Colorado, 390 UCB, Boulder, Colorado 80309, USA \\ ${ }^{2}$ Department of Physics, Hamline University, 1536 Hewitt Ave, St. Paul, Minnesota 55104, USA \\ ${ }^{3}$ Department of Physics and Mallinson Institute for Science Education, Western Michigan University, \\ 1903 W. Michigan Ave., Kalamazoo, Michigan 49008, USA
}

(Received 25 March 2019; published 4 December 2019)

\begin{abstract}
Many physics faculty are aware of and interested in using research-based instructional strategies. However, knowledge and motivation are not sufficient to support successful and sustained adoption. To address this problem, we present a faculty online learning community (FOLC) model for educational change and describe its application (the New Faculty Workshop FOLC, NFW-FOLC) to provide a year of support to new faculty following attendance at the Physics and Astronomy New Faculty Workshop. FOLCs are an extension of the faculty learning community model. Here we present the theoretical underpinnings of the general FOLC model, the design principles of our particular NFW-FOLCs, and the learning objectives for NFW-FOLC participants. We demonstrate the efficacy of our NFW-FOLCs by analyzing postexperience interviews with participants from the first four NFW-FOLC cohorts. The primary motivation given by faculty for joining our FOLCs is to improve their teaching as they learn more about teaching strategies, get implementation help, and connect to a broader community. These motivations align with our NFW-FOLC design principles. Participants overwhelmingly report the experience was valuable and impacted them positively with the most commonly reported impacts of NFW-FOLC membership being changes in their implementation of teaching strategies, increased reflection about teaching, increased confidence as teachers, increased knowledge about teaching, benefits to their students, time saved, and gaining a resource. The reported impacts provide evidence that the NFW-FOLC is successfully meeting its goals. We argue that the reported impacts are uniquely supported by the FOLC model of professional development. We advance FOLCs as a generalizable model of professional development offering a number of advantages over traditional reform efforts as well as traditional Faculty Learning Communities.
\end{abstract}

DOI: 10.1103/PhysRevPhysEducRes.15.020147

\section{INTRODUCTION AND MOTIVATION}

We present a faculty online learning community (FOLC) model of professional development for educational change. FOLCs, an extension of the faculty learning community (FLC) model, typically bring faculty together virtually for periodic meetings over the course of a year or more to support teaching growth. FOLC members are united by a common pedagogical interest. Teaching growth is accomplished through a supportive community in which members troubleshoot teaching challenges and learn from peers and experts in education. FOLCs are designed to increase the sustained adoption of research-based instructional strategies and to foster lifelong reflective practitioners who will continue learning and improving their teaching throughout their

*alexandra.lau@colorado.edu

Published by the American Physical Society under the terms of the Creative Commons Attribution 4.0 International license. Further distribution of this work must maintain attribution to the author(s) and the published article's title, journal citation, and DOI. careers. We present FOLCs as a needed improvement upon the more commonly used development and dissemination (D\&D) model for educational change. In this paper, we describe and critique the D\&D model, highlight ways the FOLC model addresses D\&D shortcomings, and then present an application of the FOLC model to support physics faculty who attend the Physics and Astronomy New Faculty Workshop (NFW); these are our new faculty workshop FOLCs. We provide data from the first four NFW-FOLC cohorts indicating that our implementation of the FOLC model appears to be working as theorized. We use this as evidence to argue for the efficacy and generalizability of the FOLC model.

A research-based instructional strategy (RBIS) is a teaching method, generally student centered and active-engagement based, that has been developed through an iterative cycle of research and design [1,2]. Examples include Just in Time Teaching [3], Interactive Lecture Demonstrations [4], ScaleUp [5], and Peer Instruction [6,7]. RBISs encompass both research-based curricula and research-based pedagogies. Commonly, RBISs are spread to faculty through dissemination-oriented methods such as talks, workshops, websites, 
and journal articles. This strategy works well for increasing awareness of innovations [2]. Additionally, many faculty are interested in implementing these innovations since they often fit their own teaching intuitions and are typically supported by data showing increased student outcomes. However, evidence indicates that while knowing about innovations and being motivated to try them can result in attempts by faculty to change their instruction, knowledge and motivation alone are insufficient to bring about sustained and impactful change [2]. In a survey of physics faculty it was found that one-third of faculty who tried an innovation report discontinuing its use [2]. This represents the largest loss in the adoption process and suggests that efforts to support faculty in continuing use are needed $[2,8]$. Additionally, while it is expected that faculty will make some adaptations to an RBIS so it fits their local population and needs, it is not uncommon for a faculty member to modify a new instructional strategy to such an extent that the outcomes are in line with traditional instruction $[9,10]$. These findings indicate there is a need to reenvision change efforts to address the high rate of abandonment and ineffective modification by faculty who are interested in and willing to engage in changing their instruction to align with research-based practices. In this paper we offer a model for educational transformation that addresses these challenges. In the next section we discuss typical change efforts and offer insights into why they fail to bring about sustained and impactful change.

\section{A. Development and dissemination (D\&D) model critique}

The FOLC model is designed to supplement change efforts that operate within the development and dissemination (D\&D) model for educational change. In order to motivate the need for the FOLC model and justify design principles, we offer an analysis of the D\&D model, highlighting aspects of the model that need improvement, and discuss how the FOLC model addresses these shortcomings. We then present the FOLC model in more detail.

Under the D\&D model, experts conduct research and develop curricular materials, often in their local context with little consideration for the variety of instructional systems in which their potential adopters are embedded [11,12]. Once developers have a final product, they share the innovation and evidence of its effectiveness with potential adopters, who are expected to then implement the materials in their classrooms. This model focuses on the developer of an innovation and on the innovation itself, assuming that spreading knowledge of an innovation and the positive effects of the innovation on teaching and learning will be sufficient for widespread adoption $[11,13,14]$. While this model makes intuitive sense and is quite successful at spreading awareness of and motivation to use new RBISs, there is ample evidence that it is insufficient as a mechanism for sustained and systemic change [11,14-19].
Below we highlight some of the reasons why the D\&D model is insufficient for producing long-lasting change. Understanding where the D\&D model falls short points toward ways it can be supplemented for improved results.

\section{The D\&D model does not adequately support faculty through implementation difficulties}

The implementation of an RBIS is not trivial and faculty typically encounter problems as they try to implement a new RBIS [20]. For example, a faculty member may attempt to implement a method that utilizes group work only to find their students resist talking with each other. Or the faculty member may have difficulties finding or writing tasks for students that support productive group work. When faculty encounter these difficulties they need help figuring out solutions. If they do not have someone to turn to for ideas and support they may give up on the RBIS and could potentially decide the RBIS itself does not work. The D\&D model does not provide this support because interaction with potential adopters is limited to raising awareness of an innovation and convincing people to try the innovation [11].

\section{The D\&D model does not support faculty in adapting RBISs to their unique local environment}

It is rare for a faculty member to be able to take an RBIS and adopt it "as is" into their local environment. The demographics of their students may be different than the population for which the RBIS was developed, or they may have to adapt to a much larger class size, or differing content coverage expectations, etc. Under the D\&D model faculty must make decisions about how to adapt an RBIS on their own, with little guidance. Developers under the D\&D model do not focus on the fit of their innovation to the different contexts of potential adopters $[8,11,12]$. While many faculty are able to navigate this challenge, research $[9,10]$ suggests that many either modify the RBIS to such an extent so as to lose its positive outcomes, or faculty may get frustrated and simply abandon the RBIS.

\section{The D\&D model views faculty as passive receivers of teaching knowledge}

Under the D\&D model experts (for example, education researchers) develop materials and faculty are viewed as passive receivers [12]. It is assumed that evidence of an innovation's efficacy is a sufficient condition for adoption, and any resistance to change can be overcome by more evidence [11]. Changes to the innovation by adopters are often discouraged. The model does not encourage faculty to view themselves as capable of taking an active role in instructional decisions, or to view themselves as knowledgeable experts of their own instructional systems. By ignoring the importance of the fit of an innovation, the 
D\&D model does not empower faculty to reflect on their unique teaching situation nor does it acknowledge that faculty are experts about their own students.

\section{The D\&D model assumes faculty can implement RBISs if they want to without acknowledging structural, environmental, and cultural barriers faculty may face}

Many faculty are in situations that perfectly support a traditional lecture-based model of teaching and conflict with many research-based reforms. For example, they teach in rooms with chairs bolted to the floor, have expectations of content coverage they have little control over, or have colleagues who teach traditionally and cannot provide resources or role models for a new approach. The failure to account for structural barriers can result in a tendency to blame faculty for not changing their teaching while simultaneously failing to support faculty to overcome very real barriers they have little power to change [11].

\section{The D\&D model does not encourage faculty to develop as reflective teachers with a growth mindset}

As detailed above, successful implementation of a change in one's teaching is not an easy process. Faculty may have the best of intentions for changing their teaching practices, but that does not always equate with successful behavioral change. The D\&D model does not help faculty develop realistic expectations about the challenging nature of implementing an RBIS effectively in their classroom. This is because emphasis is placed on the innovation itself, with little attention paid to the potential adopters and their affordances and barriers to change [11,12]. With the D\&D model, faculty may come to believe that if their initial implementation of an RBIS fails, that means the strategy itself does not work, or they as the teacher are incapable of using the strategy correctly. In other words, the D\&D model for educational change does not support the development of a growth mindset [21] and it does not give attention to the development of reflective practice. Therefore, faculty may fail to see teaching as a process of continual improvement and they may not develop the perseverance that they need to succeed.

The D\&D model for educational transformation appears to be a good start as it is effective at raising knowledge of innovations and encouraging faculty to try them [2]. However, it is insufficient because it does not address the difficulties faculty face when implementing a new technique, it does not support them adequately in using RBISs, and it does not support their development of a productive mindset towards teaching wherein teaching is seen as a process of continual improvement.

An alternative model for change, promoted in response to the shortcomings of the D\&D model, is the propagation paradigm [11,22]. Under the propagation paradigm, focus is placed on the users, and the potential adopters, of an innovation [11,14]. There are three essential propagation activities: interactive development, interactive dissemination, and support of adopters. While the efficacy of an innovation is still important under this paradigm, there is also emphasis on the fit of an innovation to different instructional systems. This is why developers following this paradigm are in dialogue with potential adopters from the earliest stages of product development through dissemination and implementation. It is assumed that any innovation will likely have to undergo some modification as adopters implement the innovation in their local context, and because of this developers should interact with adopters in order to support their implementation. While the propagation paradigm suggests that developers are in the best position to provide interactive dissemination and support, many developers are not willing or able to do so.

The FOLC model is aligned with the propagation paradigm. Importantly, FOLCs provide a way to disseminate interactively and support adopters' implementation of innovations that does not rely on the original developers of an innovation. With this added step of supporting implementation, FOLCs supplement a main shortcoming of the traditional D\&D model. FOLCs recognize the importance of the fit of an innovation to adopters' local contexts. As we will illustrate below, in supporting implementation, FOLCs acknowledge, and indeed expect, users to encounter barriers and they aid users in reflecting on and surmounting these difficulties. These aspects of the FOLC model are consistent with the assumptions of the propagation paradigm and address the areas in which traditional D\&D efforts are lacking.

In the following, we describe in more detail both the FOLC model in general and how we applied it to a specific audience. We present the design principles we use to foster the success of our application of the model, the NFWFOLC. We elaborate on the reasons for these principles and how they were operationalized in order to achieve our goals. Finally, in order to test the assumptions behind our specific implementation of the FOLC model and the mechanisms by which it is hypothesized to work, we present data on the participants' reports of why they signed up for the NFW-FOLC and what impacts they felt the FOLC had on them and their teaching. We use the results from the NFW-FOLC as support for the FOLC model overall.

\section{WHAT IS A FACULTY ONLINE LEARNING COMMUNITY (FOLC)?}

\section{A. FOLCs: An extension of faculty learning communities}

The FOLC model was designed around the faculty learning community (FLC) model of professional development. Both FLCs and FOLCs are examples of a Community of Practice (CoP) [23]. As Etienne Wenger describes, "A 
community of practice is a learning partnership related to a domain of practice" [24]. Communities of practice are defined by three dimensions: a joint enterprise, mutual engagement, and a shared repertoire [23]. The construct of joint enterprise encompasses the purpose of the community to learn and develop competence in a domain of practice [24]. Mutual engagement refers to the relationships between community members; in order to belong to a $\mathrm{CoP}$, members must be engaged together in the joint enterprise of the CoP and must trust each other in the learning process $[23,25]$. Shared repertoire encompasses the jointly constructed resources (e.g., language, tools, artifacts, and styles of interaction) needed for negotiating meaning in the community $[25,26]$. Communities of practice are premised on a social and situated view of learning [27].

The FLC model is a particular enactment of the tenets of a CoP. The goal of the FLC model is to support the transformation of faculty's teaching practices and, subsequently, students' educational experiences; this is the joint enterprise of a FLC. A typical FLC is a faculty group that "engage[s] in an active, collaborative, year-long program with a curriculum about enhancing teaching and learning and with frequent in-person seminars and activities" [28]. Participants learn with and from each other, mutually engaging in activities and developing and sharing resources. FLCs focus on building a community of support around teaching and learning and members establish norms for interacting in the community. Through the extended experience and numerous activities, FLCs give participants the opportunity to deeply reflect on their teaching. Evidence shows that FLCs increase faculty interest in teaching and learning and provide support to change longstanding instructional practice [29,30]. The FLC model was largely developed at Miami University of Ohio. Implementation details and research on FLCs have been extensively reported elsewhere [31-36]. [Similarly, professional learning communities (PLCs) have goals aligned with FLCs but exist in the K12 space to support the professional development of K12 educators. These have also been the subject of previous work [37-41]].

FLCs are traditionally conducted in a face-to-face setting on a particular campus with faculty from multiple disciplines at a single institution. The FOLC model of professional development for educational change builds on the traditional FLC design, but is different in two key ways:

\section{A FOLC meets virtually rather than in person}

A FOLC is conducted in a virtual, rather than face-toface, environment using teleconference technology for synchronous meetings and an online platform for asynchronous discussion between participants. This is potentially negative as it is more difficult to establish rapport and a sense of community online. However, as we show later in this paper, it is still possible. Further, the online environment offers several distinct advantages as detailed below.

\section{A FOLC is composed of faculty from multiple institutions, allowing for more targeted professional development}

Because meetings are virtual there is no need for participants to be geographically close. This presents a great advantage as we can form a FOLC composed of faculty with more uniform concerns and interests. This means, for example, that there can be a FOLC of faculty from only one discipline (traditional FLCs span multiple disciplines). Further, FOLCs can be specific to even a subset of faculty such as new faculty or faculty all teaching the same course. This allows for more specific support than is possible in a traditional FLC. Also, an advantage afforded by having faculty across institutions is that group members are not in the awkward position of having to evaluate one another, which allows them to be more open and vulnerable about difficulties they may be having. And finally, it affords participants the opportunity to learn about how other institutions operate and how issues may be navigated differently.

\section{B. Application of the folc model: the physics and astronomy new faculty workshop and the NFW-FOLC}

The physics and astronomy new faculty workshop (NFW) [42] is offered twice a year, typically in November and June, for faculty in their first few years of teaching. For three days faculty from across the country attend talks and workshops by leaders in physics education, exposing them to numerous research-based instructional strategies. From previous work, we know that the NFW is highly successful at increasing awareness of research based instructional strategies among faculty participants and motivating them to try to transform their teaching but faculty use of these RBISs drops off over time [2]. For example, a logistic regression analysis performed on survey data of physics faculty found the largest correlation with trying an innovation was attendance at the NFW [2]. NFW attendees were 7 times more likely to report having tried an innovation than nonattendees.

A multiday workshop such as the NFW can be very impactful at increasing knowledge and desire to use RBISs in faculty, and such learning opportunities are an essential component of a successful model of educational transformation. However, a short-term workshop, or even a series of similar professional development opportunities, are insufficient to fully support faculty through the implementation process as discussed in the critique of the $\mathrm{D} \& \mathrm{D}$ model above.

FOLCs, designed and implemented to address the ways in which the D\&D model is insufficient, represent one potential solution to these challenges. Faculty who attend the physics and astronomy new faculty workshop are given the opportunity to participate in a year-long virtual community to support their ongoing professional development 
through biweekly virtual meetings and an online platform to facilitate asynchronous communication.

\section{Detail on the NFW-FOLC structure}

A NFW-FOLC cohort is comprised of, on average, nine new physics and astronomy faculty members who attended the same in-person NFW. Each cohort is facilitated by one or two more experienced physics or astronomy faculty members. After the first two cohorts, we recruited facilitators from past FOLC participants. At the NFW the FOLC facilitators advertise the program to attendees and the new faculty members have the chance to sign up. We start a new cohort every semester, in conjunction with each offering of the NFW.

A FOLC cohort meets every other week via a video conferencing platform and members can communicate in between meetings via a private online platform. The cohort meets for a full year following the NFW. During the synchronous video meetings, FOLC members give updates on their teaching and troubleshoot issues with each other. While the focus is on teaching, unsurprisingly these new faculty members also bring up challenges associated with their jobs generally, such as tenure and promotion, finding research collaborators, etc. In about half of the meetings, guest speakers are invited based on FOLC members' interests to talk about particular teaching strategies. The guests are often experienced practitioners of the teaching strategy being discussed. Guest speakers are encouraged to have a dialogue with FOLC participants and participants can submit questions for the speaker before the meeting. FOLC members complete a scholarship of teaching and learning (SoTL) project during the second half of their FOLC experience $[43,44]$. With this project, members are encouraged to choose an aspect of their teaching they would like to change, implement that change, assess the change, and present the results to their cohort. Periodic FOLC meetings are devoted to discussing progress on the SoTL projects and possible assessment strategies. In between the synchronous meetings, participants can share resources, ask questions, and follow up on discussions using the asynchronous communication platform.

\section{DESIGN PRINCIPLES OF THE NFW-FOLC}

In this next section we describe design decisions around the NFW-FOLC. These decisions are based on the hypothesis that faculty need more than knowledge of an innovation and motivation in order to succeed at implementation, as detailed above in the critique of the D\&D model. In designing the NFW-FOLC our primary goals for the participants were to help them develop as reflective practitioners committed to continual teaching improvement and to support them in successfully implementing RBISs. We define successful implementation as one that is sustained over the long term and that is adapted to the local environment while still aligning with recommendations from the research literature. These primary goals of the NFW-FOLC reflect the areas in which the D\&D model falls short and are consistent with the propagation paradigm.

In order to reach these large goals there were several "learning objectives" for the participants that we designed the NFW-FOLC to achieve. Underlying these learning objectives is the overarching objective that participants' students experience better learning outcomes. This is the ultimate goal of the FOLC: to improve students' learning experiences by improving the teaching practices of their instructors. The six learning objectives for FOLC participants listed below are actions associated with improved student outcomes.

The NFW-FOLC participants will

1. Develop reflective teaching habits and a dedication to continuous improvement of teaching.

2. Increase their knowledge and awareness of RBISs.

3. Maintain or increase their motivation to implement RBISs in their classrooms.

4. Implement RBISs in their classrooms consistent with recommendations from research.

5. Persist in their implementation of RBISs.

6. Increase their sense of empowerment regarding themselves as teachers (includes confidence using RBISs, agency, and self-efficacy).

Below we describe NFW-FOLC design principles that were explicitly utilized in order to meet the objectives listed above. The design principles frequently address multiple learning objectives. In addition to building off FLC design, these principles are consistent with design principles found in K12 professional development programs $[45,46]$. Table I summarizes our design principles and objectives.

\section{A. Provide ongoing opportunities for participants to continue learning about RBISs}

A significant portion of the biweekly virtual meetings during the first semester was set aside for guest speakers. Participants were periodically asked what they wanted to learn more about and then the facilitator and project team would look for an appropriate speaker for an upcoming meeting. Based on participant feedback from early FOLC cohorts, an effort was made to find a guest speaker who was not a developer or researcher of a RBIS but rather a practitioner with extensive experience in implementation. Speakers were encouraged to structure their visit to be heavy on discussion and light on presentation. Facilitators sometimes collected questions from the participants for the speaker ahead of time. Thus, participants in the FOLC received ongoing professional development related to increasing their knowledge and awareness of RBISs based on their own interests and needs. 
TABLE I. The NFW-FOLC design principles and learning objectives. The design principles often serve multiple objectives.

Design principles Learning objectives

- Provide ongoing opportunities for learning about RBISs

- Provide ongoing feedback and support to help through implementation difficulties

- Encourage a sense of safety and a willingness to be vulnerable within the group

- Enact a structure that encourages and values the expertise of all participants

- Encourage completion of a Scholarship of Teaching and Learning (SoTL) project during the second half of the experience

- Foster a supportive community

\section{B. Provide ongoing feedback and support to help participants through implementation difficulties}

As mentioned above, participants had ongoing opportunities to ask questions of experienced practitioners of methods they were implementing or had interest in implementing. Further, a significant portion of each virtual meeting was set aside for discussions among group members. Typically, this group discussion time was initiated by a round of what we call "best and worst." Each member of the FOLC, including the facilitators, would share something from their teaching that week that they were proud of and something that they did not feel went well. This encouraged each member to share something they were struggling with and provided encouragement to the group to offer suggestions, feedback or even simple affirmation of the person's frustrations. Additionally, in between meetings participants could pose questions or quandaries about their teaching to the group through the asynchronous communication board and receive support between meetings. These structures meant that at any point a participant could get feedback if they were having difficulties. Even if they did not explicitly ask for feedback, they would be prompted to do so at least biweekly.

\section{Encourage a sense of safety within the group and a willingness to be vulnerable}

In order to be able to share difficulties openly and therefore learn and get feedback, participants had to feel safe admitting when things were not going well. The best and worst activity described above, while intended to elicit difficulties, was also intended to develop feelings of safety. Facilitators were encouraged to share their own difficulties, modeling a willingness to acknowledge mistakes and imperfections. By having each person share their difficulties, the participants were continually reminded that everyone was struggling, and they were often struggling with similar issues. It was our hope participants would feel more comfortable talking openly about their own challenges.
- Participants develop reflective teaching habits and a dedication to continuous improvement of teaching

- Increase participants' knowledge and awareness of RBISs

- Maintain or increase participants' motivation to implement RBISs in their classrooms

- Participants implement RBISs in their classrooms consistent with recommendations from research

- Participants persist in their implementation of RBISs

- Increase participants' sense of empowerment regarding themselves as teachers (includes confidence using RBISs)
This normalizes struggles as a part of teaching and encourages a growth mindset. Further, it was established as a norm that discussions specific to individuals should be treated confidentially. And finally, lurkers were not allowed. If a participant ceased to be an active member of the group they were removed from the group and no longer had access to the asynchronous communication board.

\section{Enact a structure that encourages and values the expertise of all participants}

As mentioned above, it was our goal to empower the participants. The FOLC therefore was organized as a community effort rather than a top-down structure. Our facilitators are so named, rather than called "leaders," to reflect this choice. As much as possible, FOLC facilitators were previous FOLC participants; therefore, they were also younger faculty who were learning along with the participants. Facilitators were encouraged to not dominate discussions, therefore setting the norm in both the synchronous and asynchronous interactions that everyone would help each other and not look to the facilitators as the experts. For example, facilitators waited to post a response on the asynchronous board so others could share first. Every participant was treated as having valuable knowledge to share with the group. The facilitators sharing a difficulty in their teaching during the best and worst activity (described under No. C above) was also meant to show participants that even more experienced practitioners are not perfect and have not figured out every teaching problem. It was our hope that the focus on distributed expertise would help participants develop their self-efficacy around teaching and develop a growth mindset towards teaching as a process of continual improvement.

\section{E. Encourage completion of a scholarship of teaching and learning project during the second half of the experience}

All participants were asked to engage in a SoTL project $[43,47]$ during the FOLC. The scholarship of teaching and 
learning is frequently cited as an important component of in-person FLCs [28]. By engaging in a SoTL project, FOLC participants identified an aspect of their teaching to explore, took data in order to understand this aspect better, and then shared their results with their peers. With the support and feedback of the FOLC cohort, participants formulated ways to answer their questions about their teaching and enacted those plans. In other words, SoTL projects allowed participants to practice assessing changes they made in the classroom rather than relying only on intuition about how the technique worked. By guiding FOLC participants through one iteration of asking and answering a question about their own teaching, we hoped these projects would foster reflective thinking and motivate participants to assess their teaching practices going forward. Further, through engaging in SoTL projects we aimed to instill in participants an attitude towards teaching as a process of continual improvement and to encourage a growth mindset.

\section{F. Foster a supportive community}

Finally, the FOLC was designed to foster a community of support. This design principle addresses every FOLC learning objective and we believe it is in fact the most critical design feature. At its core the FOLC was designed to be a community. As discussed above, implementing and sustaining the use of RBISs is difficult and we hypothesize that having a nurturing and supportive professional community can help faculty productively change their teaching and sustain those changes. In designing the FOLC much effort was put into building the community aspect. For example, participants were encouraged to get to know each other during meetings through the best and worst activity and informal chatting at the beginning and end of meetings. There was always time reserved during meetings for the cohort to interact without outside guest speakers. Facilitators also encouraged participants to post brief "What's going on this week" updates on the asynchronous site between meetings. The very choice to have an asynchronous platform was made with community formation in mind. We felt that interacting once every other week was not enough to sustain connections and an asynchronous platform would allow the cohort communicate at any time.

Additionally, this design principle is bolstered by other design principles listed above. "Encouraging a sense of safety within the group" was also meant to connect the group emotionally and make it feel like a community. "Valuing the expertise of all participants" and "providing ongoing feedback" encouraged participants to share ideas and connect intellectually.

Through these learning objectives and design principles we target areas in which the D\&D model is insufficient for producing sustained change. Namely, we support participants over time as they work through implementation difficulties while encouraging them to reflect on their teaching more generally. This is all accomplished with the support of a community. These principles and goals further reflect the model of change espoused by the propagation paradigm in which supporting adopters is a key tenet for successful, long-term change.

So far in this paper, we have presented shortcomings of the D\&D model and ways the FOLC model would be expected to address these shortcomings (e.g., by focusing on providing implementation support, developing reflective practice of participants, etc.). We have detailed one particular instantiation of the FOLC model: the design principles and goals of the NFW-FOLC. We now turn to evidence of effectiveness of the FOLC model. NFW-FOLC data collection and analysis is extensive and ongoing. Below we focus on answering two questions. First, is our implementation of the FOLC model fulfilling a need as hypothesized and, second, are there indications that our application of the model is working as intended? Specifically, we report on an analysis of interviews conducted with participants during or immediately following the NFW-FOLC experience. Encouragingly, self-reports from participants in their interviews indicate we are largely meeting our goals and our design principles are working as anticipated.

\section{METHODOLOGY}

\section{A. Data sources and analysis}

The NFW-FOLCs have been running since Spring 2015 with two cohorts starting each year to coincide with the two offerings of the NFW. During that time we have collected a large amount of data including pre-post and longitudinal surveys from NFW evaluation data, interviews with participants at the end of their FOLC experience, surveys of participants' experiences of the FOLC community and their teaching practices, videos of virtual meetings, and archives of asynchronous communications. Additionally, we are collecting longitudinal data in the form of additional participant interviews two years after they complete the experience, to understand long term impacts of the FOLC. It is beyond the scope of this paper to offer a full analysis of all the data collected. In this paper, we analyze interview data collected at the end of participants' time in the FOLC.

We invited all forty participants from the first four cohorts to participate in video interviews about their experiences in the FOLC. Thirty-four participants accepted. For cohort one, these interviews occurred approximately midway through their time in the FOLC. Because this was our first cohort, we ran it as a one-semester pilot and we wanted to get feedback from members before the end of the semester. For cohorts two through four, we conducted interviews with members after they completed their year in the FOLC.

In the interview, we used a semistructured protocol. Members of the research team conducted the interviews. 
Participants and interviewers had limited interactions prior to the interviews. Participants were informed that their interviews would not be shared in any identifiable way with their facilitators. Interviewers made clear that they wanted to know both what in the FOLC had worked well and what had not worked well for the participant. In these ways, we worked to minimize the influence of the interviewer on the interviewee's responses. Participants were asked general questions about how the FOLC went and what they liked and did not like about the experience. They were asked about their motivation for joining the FOLC and if they found the experience worthwhile. They were also asked about their teaching and how it has been impacted by the FOLC. Additionally, participants were asked about the different components of the FOLC (synchronous meetings, asynchronous communication, and SoTL projects) and about their impressions of the community which developed among their cohort. In this paper we will report on participants' motivations for joining the FOLC and on their self-reported impacts of participating in the FOLC.

For the interviews from the first three cohorts, two of the authors (A. L. and M. D.) coded the interviews. On a first pass, we used organizational categories to sort the data into the major topics discussed [48]. All the responses related to their motivation to join the FOLC were coded as motivation. This was frequently in direct response to the question "Why did you join the FOLC?". Likewise, anytime the participants spoke about how the FOLC has impacted them, that was coded as an impact. These impacts arose throughout the interview and not just in response to a specific question. We then developed (separate) subcoding schemes for the motivation responses and impact responses. These subcodes were developed inductively [49]; some of the categories of the subcoding scheme were developed based on the patterns we had seen in our first pass at coding, while others emerged as we went through the responses the second time. The subcodes are substantive categories, capturing with more detail the specific content that was expressed by participants [48]. The two authors subcoded all the entries separately and then compared their coding for each entry until total agreement was reached.

Around 6 months after the coding of the first three cohorts' interviews, one of the authors (A. L.) began coding the by-then-collected interviews from cohort four. This author followed the same procedure described above for capturing the major themes of the interview. (Responses to the motivation question were again coded as such and impacts were noted throughout the interview). On a second pass through this set of interviews, this author attempted to subcode the motivation and impact excerpts according to our previously developed coding scheme. In doing so, she noticed themes in the interviews that were not sufficiently captured in the existing coding scheme. After discussing these gaps with the author (M. D.) involved in the coding of the first three sets of interviews, we decided to amend our subcoding schemes, adding a few new codes, specifying definitions of existing codes, and reorganizing the code structure as made sense. A. L. then applied these modified subcoding schemes to the motivation and impact excerpts from the cohort 4 interviews. Any time she was unsure of how to code a segment, the segment was discussed with M. D. and the two authors then agreed on the code that fit.

After completing the coding of the cohort 4 interviews, A. L. went back to the interviews from the first three cohorts and revised their coding based on the modified coding schemes. Again, any time there was a segment A. L. was unsure how to code, it was discussed with M. D. until agreement was reached.

Once the coding and recoding of all interviews was complete, we found that some of our codes were capturing a wide range of experiences. We decided to further break down these codes into more specific codes. For example, we noticed that the types of knowledge participants reported learning because of their participation in the FOLC fell into three distinct categories. We decided to subcode all knowledge excerpts into these three categories in order to have a more fine-grained analysis. The data presented in this paper is a result of our highly iterative cycle of coding and refinement.

\section{B. Participants}

As of Fall 2018 we have run nine cohorts, with a total of 82 people enrolled in the NFW-FOLC. (The participants we have interviewed are part of the 82 people). Members of a given FOLC cohort all attended the same in-person NFW. Out of all our participants, 71 have reported on their gender and 63 have reported on their race and/or ethnicity. Institution-type data are either self-reported or determined by the authors for all 82 participants. Of the 34 participants we interviewed, we have information on gender for 24 of them and information on race and/or ethnicity for 19 . Table II shows the demographic characteristics for the interview participants, the NFW-FOLC population overall, and the NFW population. For the NFW population, gender and race data were collected for 290 participants, while institution-type information was collected for 161 participants.

Our FOLC participants are self-selected. They have chosen to attend the NFW and from there have chosen to participate in the FOLC. Demographically, they are not representative of either all new physics faculty $[50,51]$ nor of the NFW participants overall. Specifically, our participants are more likely to be female ${ }^{1}$ and more likely to come from a primarily undergraduate institution. However,

\footnotetext{
${ }^{1}$ This is aligned with the results of previous studies which have found that females are more likely than males to hold teaching beliefs and practices aligned with interactive engagement methods [52] and that being female is a significant predictor of continuing use of an RBIS [2].
} 
TABLE II. Demographic characteristics for interviewees, NFW-FOLC participants overall, and NFW attendees. Demographic data are reported based on collection categories which were not identical across groups. Note, the NFW population institution-type data is aggregated over the June 2016 through June 2017 workshops.

\begin{tabular}{|c|c|c|}
\hline Interview participants & NFW-FOLC participants & NFW population overall \\
\hline $\begin{array}{l}\text { Members from the first four cohorts, } \\
\text { January 2015-June } 2017\end{array}$ & $\begin{array}{l}\text { Aggregated over all } 9 \text { cohorts, January } \\
\text { 2015-September } 2018\end{array}$ & $\begin{array}{l}\text { Aggregated over June } 2015 \text { through June } \\
2017 \text { Workshops Pre-Survey }\end{array}$ \\
\hline Female: $46 \%$ & Female: $45 \%$ & Female: $30 \%$ \\
\hline \multirow[t]{2}{*}{ Male: $54 \%$} & Male: $52 \%$ & Male: $67 \%$ \\
\hline & $\begin{array}{l}\text { Transwoman: }<5 \% \\
\text { Agender: }<5 \%\end{array}$ & Prefer not to answer: $<5 \%$ \\
\hline White or Caucasian: $84 \%$ & White or Caucasian: $79 \%$ & White or Caucasian: $61 \%$ \\
\hline Asian: $<5 \%$ & Asian: $11 \%$ & $\begin{array}{l}\text { Asian or Pacific islander: } 22 \% \text { Asian or } \\
\text { Pacific islander and White or Caucasian: } \\
<5 \%\end{array}$ \\
\hline Black or African American: $<5 \%$ & Black or African American: $<5 \%$ & Black or African American: $<5 \%$ \\
\hline \multirow[t]{4}{*}{ Hispanic or Latino: $<5 \%$} & Hispanic or Latino: $<5 \%$ & Hispanic or Latino: $<5 \%$ \\
\hline & White, non-Anglo: $<5 \%$ & Hispanic or Latino and White or Caucasian \\
\hline & White-Hispanic: $<5 \%$ & $<5 \%$ \\
\hline & & $\begin{array}{l}\text { American Indian or Alaskan Native: }<5 \% \\
\text { Prefer not to answer/NA: } 8 \%\end{array}$ \\
\hline Ph.D. granting institution: $24 \%$ & Ph.D. granting institution: $29 \%$ & Ph.D. granting institution: $42 \%$ \\
\hline Masters granting institution: $9 \%$ & Masters granting institution: $6 \%$ & Masters granting institution: $5 \%$ \\
\hline Primarily undergraduate institution: $68 \%$ & Primarily undergraduate institution: $65 \%$ & Primarily undergraduate institution: $52 \%$ \\
\hline
\end{tabular}

from postworkshop survey data collected just after the NFW but before participation in the FOLC, we found FOLC participants were similar to NFW participants who did not join the FOLC in self-reported motivation, knowledge, and confidence in using active learning strategies [53].

\section{FINDINGS AND DISCUSSION, PART 1: MOTIVATIONS FOR JOINING THE NFW-FOLC}

\section{A. Results-analysis of motivations for joining}

Why do faculty join the NFW-FOLC? Is their motivation to participate consistent with our philosophy, goals, and design principles? In order to help understand the FOLC participants and their expectations we read through the interviews and coded all instances where they were talking about their motivation to join the FOLC. Typically, this was in response to the direct question "Why did you join the FOLC?" Perhaps unsurprisingly but significantly, all thirtyfour interviewees (from our first four cohorts) expressed a desire to improve their teaching and develop as a teacher as a reason for joining the FOLC. Eight participants did not specify beyond that. Of the participants who did specify further, their responses tended to fall into three broad categories: desire to expand their professional community; getting implementation help; and learning more about teaching strategies. Responses could be co-coded into multiple of these categories. These results are displayed in Table III. It is important to note that these are responses given spontaneously; we did not directly ask, for example,
"Did you join the FOLC to get implementation help?" Therefore, we expect that a larger percentage would likely have agreed each was a reason for joining than brought it up on their own as reflected in the data table.

\section{Learn more about teaching strategies}

Nearly one-quarter of interviewed participants expressed that one of the reasons they joined the FOLC was to learn new things about teaching. This code captures participants' desire to increase their teaching knowledge. For example, one participant stated, "I was interested in blocking out some time, basically, to make myself learn more about teaching and learning." This sentiment of wanting to learn more was echoed by another participant who stated that one of the reasons they joined was because they were, "very interested always in just learning new techniques, learning to be more active and interactive." One member was more specific and stated that they joined to learn more about pedagogy they could apply to their upper-division courses.

TABLE III. Specified motivations for joining the NFW-FOLC, beyond "to improve my teaching." People could fall into more than one category. Count represents the number of participants coded to a category. Percentages are out of 34 participants.

\begin{tabular}{lccc}
\hline \hline Code & $\begin{array}{c}\text { Learn more } \\
\text { about teaching } \\
\text { strategies }\end{array}$ & $\begin{array}{c}\text { Get } \\
\text { implementation } \\
\text { help }\end{array}$ & $\begin{array}{c}\text { Expand } \\
\text { professional } \\
\text { community }\end{array}$ \\
\hline Count & 8 & 16 & 25 \\
Percent & 24 & 47 & 74 \\
\hline \hline
\end{tabular}


This motivation to join the NFW-FOLC is consistent with our design principle of providing ongoing opportunities for participants to continue learning about RBISs. Our participants wanted opportunities to learn more about teaching and we have designed the FOLC to provide those opportunities. It is important to note, however, that no participant expressed learning new content as their sole reason for joining the FOLC. Our participants did not want just an extension of the types of presentations they had at the NFW.

\section{Get implementation help}

Nearly half of the interview participants said that one of their motivations for joining the FOLC was to get help implementing RBISs. These participants described a desire to get feedback from the FOLC community as they implemented new teaching techniques; they wanted to increase the usability of knowledge they gained at the NFW. One participant coded in this category said, "It's very overwhelming when you get to that meeting [the $N F W]$ and you see all of these different techniques and how people do it. I was like okay, maybe I need some help to implement some of that stuff." Participants were inundated with information about many different teaching methods at the NFW and they saw the FOLC as a means to help develop their skills in implementing the techniques they had learned about.

Another FOLC member relayed, "I signed up after I taught my first class ever, which I thought was a big disaster... Yeah, so it [signing up for the FOLC] was just to be able to get more guidance and feedback and enhancing my teaching experience." This faculty member was very new to teaching and believed the FOLC would give them feedback on what they were trying in their teaching. Even faculty members more versed in RBISs were motivated to join the FOLC for the implementation help: "I thought it was a very fun way to chat and to kind of work out these problems with a cohort of people. Because I had learned some PER stuff before and knew the gist of it, I also learned that implementing it was a real pain in the butt." Based on their prior experience, this FOLC member knew that implementing an RBIS could be challenging and they saw the FOLC as a way to mediate potential implementation difficulties.

One of our participants specified that they joined to have, "A place you can talk to other people: hey I did clicker questions and I'm having a terrible time keeping my kids on task, what do you do? Just things like that are what I was really looking for when I signed up... Being able to bounce ideas off people and share ideas." This participant joined the FOLC to have a forum where they could troubleshoot the nitty-gritty details of the RBISs they were trying in their classroom. Also, the motivation to "bounce ideas off people" in order to improve the implementation of a teaching technique was echoed by multiple participants in describing their motivation to join the FOLC.
This motivation to join the NFW-FOLC is consistent with our design principle of providing ongoing feedback and support to help participants through implementation difficulties. Based on previous research [20,54], we know faculty members encounter a number of challenges when implementing RBISs and we designed the FOLC to help faculty persist through these challenges and see challenge as a normal part of the teaching process. Participants joining the FOLC to receive implementation support helps validate this aspect of our application of the FOLC model (and the FOLC model more generally); these participants acknowledged that taking ideas directly from the workshop and implementing them would not be trivial.

In describing their desire to receive implementation help, many participants specified that they thought they would receive this support from the people in their cohort. They were not talking about receiving this help solely from the experienced practitioner guests the cohort would invite to speak. This is consistent with the NFW-FOLC design principle of enacting a structure that encourages and values the expertise of all participants. Our participants recognized going into the FOLC that they could learn and receive assistance from their peers (and the FOLC was a space where this could occur).

\section{Expand professional community}

Three-quarters of the interviewed FOLC participants described joining the FOLC in order to expand their professional community. For example, one member explained "I went to the New Faculty Workshop and met some people there that I really connected well with and just felt like I could talk to about teaching and about classes and about all of the stress and strain of being a faculty member, and I wanted to continue that conversation, and those people were the people that ended up in the FOLC. So yeah, it [joining the FOLC] was just a way to continue that." A handful of our participants expressed this desire to "continue the conversations" started with attendees at the NFW. Of the 25 participants who talked about joining the FOLC to develop their professional community, 18 of them specified further than the above example about the types of connections they were hoping to develop. Those who specified fell into one or multiple of the following categories regarding the kind of community they wanted: connection with other new faculty; connection with people outside their local department for broader perspective; connection with people who care about teaching; connection with other faculty because of lack of sufficient local support. Table IV shows how many people were coded at each category, and we define and demonstrate each category in turn, below.

a.Connect with other new faculty.-Around one-third of the participants who expressed that they joined the FOLC to expand their professional community specified that they 
TABLE IV. The subcodes of the motivation to "expand professional community." People could fall into more than one category. Count represents the number of participants coded to a category. Percentages are out of the 25 participants who joined the FOLC to expand their professional community.

\begin{tabular}{lcccc}
\hline \hline Subcode & $\begin{array}{c}\text { Connect with other new } \\
\text { faculty }\end{array}$ & $\begin{array}{c}\text { Connect with faculty } \\
\text { outside their department } \\
\text { for broader perspective }\end{array}$ & $\begin{array}{c}\text { Connect with other } \\
\text { faculty who care about } \\
\text { teaching }\end{array}$ & $\begin{array}{c}\text { Connect with other } \\
\text { faculty due to lack of } \\
\text { sufficient local support }\end{array}$ \\
\hline Count & 9 & 4 & 4 & 12 \\
Percent & $35 \%$ & $15 \%$ & $15 \%$ & $48 \%$ \\
\hline \hline
\end{tabular}

joined to meet other early career faculty members. These FOLC members wanted to connect with other new faculty. One of the FOLC members explained, "I thought it would be good to especially talk to people who are just starting out, that are trying things out, rather than people that had a lot of experience maybe...it was good to see how people are interacting with something the first time." This participant wanted to interact with peers, people who were also new to teaching. Similarly, another participant expressed their motivation for joining the FOLC as, "Just being a part of a community where I can talk and interact with people who are going through the same things I am, you know...being able to talk things over with other people who are going through the same types of things was I think one of the things that I was really looking for." This FOLC member saw the FOLC as a way to gain a peer group, people going through the "same types of things."

b.Connect with faculty outside their department for broader perspective.-Close to $15 \%$ of the participants who wanted to join the FOLC to develop their professional community specified that they wanted to meet faculty members outside their local department and institution. One participant directly said, "It's nice to have somebody outside of my department." This participant was motivated to join to connect with people, "in addition to [their] department." Another participant expressed that they wanted to connect with faculty outside their university because, "You don't really want to tell them [your local colleagues] I don't know how to teach, help me." They saw the FOLC as a way to develop a community they could be vulnerable with in facing their teaching challenges. An additional participant said they, "wanted some contact with the outside to not just get a broader set of ideas but also to bounce some of our ideas off of other people." This FOLC member wanted to connect with people outside their department in order to gain a wider range of perspectives.

c.Connect with other faculty who care about teaching.Similarly, $15 \%$ of the participants who wanted to join the FOLC to develop their professional community said that in particular they wanted to connect with other faculty who care about their teaching and have a desire to improve. For example, one participant said the FOLC, "seemed to me like a good way of having people to turn to who are interested in and care enough [about teaching] that I trust their opinions." These FOLC members wanted to connect with other faculty who were equally passionate as them about teaching.

d.Connect with other faculty due to lack of sufficient local support.-Nearly half of the participants who wanted to join the FOLC to expand their professional community expressed wanting a community that their local environment did not provide. For example, one participant explained, "I feel like our department specifically has gotten a little old fashioned, if you will, and so I was excited to kind of think about some new strategies that could be utilized in physics but really over in engineering as well." This FOLC member did not have other faculty in their department who were interested in talking about new teaching methods and they saw the FOLC as a way to fill that gap.

Our FOLCs have also had a number of members who come from very small departments, which is not uncommon for the primarily undergraduate institutions at which a number of them work. One such participant said they joined the FOLC, "just because I thought it would help me being able to talk to other physicists, because I am the only person here, about methods and ways to improve my teaching skills in physics specifically." Another member from a one-person department stated they joined, "largely just because I didn't have anybody else to talk to about what I was doing...frankly the social aspect of it was a big draw to me." Some of our FOLC members did not have a local community of physics faculty (or that community was very small) and the FOLC supplied that community for them.

Other FOLC members were the newest members to their departments and felt they lacked a peer group in their local department. For example, a participant said they joined because, "I' $m$ the only one [in my department] on tenuretrack right now, that's not tenured and not a lecturer or a researcher, so I don't have anyone in the department to talk to about being on tenure-track, basically, or being young faculty. So I thought that would be a good opportunity for me to talk to people in physics who are in the same boat." This participant wanted to talk to people at their same career level, and the FOLC provided this opportunity. This same sentiment is echoed by another FOLC member who 
explained, "I felt like in my own department I was kind of lonely and didn't have peers, so it [the FOLC] seemed like a good way to have peers."

Either because their department was older, small, or traditional in their teaching, these FOLC members desired a community that was not possible at their local institution. Note, however, that these FOLC members often still felt supported by their local department in other ways. Indeed, some FOLC members said they loved their local colleagues, but they joined the FOLC to connect with a group of people unavailable locally.

This motivation (expanding their professional community) to join the NFW-FOLC is consistent with our design principle of fostering a supportive community. Nearly three-quarters of our participants were looking to connect with faculty with whom they could talk about teaching, and they saw the FOLC as a place where that community could form. We believed a key function of the FOLCs would be to build community and the majority of our participants were compelled to join for that reason.

The motivation to expand their professional community is also consistent with our design principle of encouraging a sense of safety within the group and a willingness to be vulnerable. In particular, some of the participants who joined the FOLC to establish connections with people outside of their local department for broader perspective explained that they could be more open about their teaching challenges with nonlocal colleagues. We expected that as new, untenured faculty, our FOLC participants would need a space where they could honestly share and receive feedback about their teaching and some of our members explicitly voiced this need in joining the FOLC. Also, it is not too much of a leap to assume that all the participants who were motivated to join the FOLC to develop professional connections wanted the community they hoped to form to be a safe and welcoming space.

Additionally, this motivation to join the NFW-FOLC is consistent with our design principle of enacting a structure that encourages and values the expertise of all participants. In joining the FOLC to develop a professional community with other faculty around teaching, our members wanted to be able to learn from peers. Our members wanted to be able to learn from other new faculty, from faculty outside their department, and from faculty who care about improving their teaching. This motivation shows that our members were not joining to only hear presentations from experienced practitioners and learn only from experts.

\section{B. Discussion of motivations for joining}

The motivations of faculty joining the NFW-FOLC provide important insights about the value and potential of the FOLC model generally and the NFW-FOLC design principles particularly. Specifically, the NFW-FOLC participants believe they need more support to implement changes than is provided by a single workshop and they value and see a need for this support to be in the form of a community. We discuss insights gained from our analysis of motivations of faculty to participate in a FOLC below:

\section{The FOLC provides desired ongoing implementation help}

The FOLC faculty are not predominantly looking for an extended workshop experience of presentation of information by experts. (Recall, no participant was solely coded at "learn more about teaching strategies" for their motivation to join the FOLC). Participants recognized that dissemination of teaching techniques is insufficient for them to make big teaching changes; they wanted implementation help from a learning community. It is important to note that faculty who attend the NFW are typically in their first few years of teaching but not their first year. Most of them have had the experience of attempting teaching and have learned more about what they need help with. These faculty have enough experience to realize they are unlikely to come away from the workshop able to implement what they have learned without difficulty. They desire the support the FOLC offers for the same reasons we offer the FOLC.

\section{The FOLC provides a valued community of support}

A large portion of our members joined for the affordances of a community. Participants talked about the value of connecting with others who cared about teaching and they also identified several desired and valuable aspects of an online community in particular. They frequently talked about a need for a community that they could not find in their offline, local environment. As a virtual community, the NFW-FOLC is able to provide support in ways inperson learning communities cannot. Departments often hire only one new member at a time, leaving new faculty without colleagues near their career stage. Departments may also be small with only a single or few faculty in physics affording little opportunity for interactions with other physics faculty. Faculty may find themselves in departments with colleagues who are not interested in teaching reforms or they may feel uncomfortable being vulnerable about their teaching difficulties with people who will evaluate them for tenure. Our participants identified all of these challenges as reasons to join the FOLC, recognizing the ability of an online community to provide these connections.

Encouragingly, the reported motivations for joining the NFW-FOLCs align with the NFW-FOLC design principles. This is confirmation from our participants that elements in the FOLC design are addressing their needs and wants. Above, we have shown how our members' motivations are consistent with five out of six of our design principles. The remaining design principle, encouraging completion of a scholarship of teaching and learning project, is consistent with participants' overarching motivation to grow as 
teachers. All of our FOLC participants were motivated by a desire to improve and develop as teachers and the goal of SoTL projects is to aid in this development.

To summarize, analysis of the motivations of faculty to join the NFW-FOLC indicate there is consistency between their needs and desires for professional development around teaching and our motivations for offering the NFW-FOLC, which are encoded in its design principles. This alignment between design and faculty members' reported teaching needs provides support for the FOLC model in general. The participants of the NFW-FOLC, an application of the FOLC model, see value in an opportunity for sustained implementation support from a peer community. While this was enacted in particular ways in the NFWFOLC, these are tenets of the FOLC model of professional development for educational change. The FOLC model serves identified needs of faculty.

\section{FINDINGS AND DISCUSSION, PART 2: IMPACTS OF PARTICIPATING IN THE NFW-FOLC}

\section{A. Results-analysis of impacts of the NFW-FOLC}

In assessing the value and success of the FOLC model and instantiations of the model, it is essential to consider impacts of the FOLC experience. Here we report on participants' self-described impacts at the end of their time in the NFW-FOLC. In order to understand the impact of the FOLC experience on participants we read through the interviews and coded all instances where they were talking about an effect the FOLC had on them, either during the experience or something they will take with them after the experience ends. We define impact as anything that had an effect on our participants' teaching beliefs, practices, and/or attitudes. Seven major themes emerged out of the nearly 300 interview excerpts that had to do with impacts of the FOLC. Excerpts were co-coded into multiple categories when applicable. Table $\mathrm{V}$ presents these categories and the number of participants who fell into each one. These categories are defined below and examples are given. As before, we note that participants were not asked about all of these impacts directly, therefore we expect a higher percentage would be likely to agree on the impact than those who spontaneously reported it. For example, our finding that one-third of participants reported increased confidence does not mean the other two-thirds did not increase their confidence, only that they did not happen to mention it on their own during the interview.

\section{Implementation change}

Over four-fifths of participants talked about an implementation change in their teaching influenced by their participation in the FOLC. This code includes members who because of the FOLC tried (or were planning to try) a RBIS, members who persisted in trying an RBIS after encountering challenges, and members who during the FOLC modified a strategy they had tested out prior to the NFW.

Regarding their approach to trying new teaching techniques, one of our participants shared, "One thing from the FOLC also, what I did not get out of the workshop, is if you try something, try it for a semester, and then you see if it works or not. If you don't try it you can't make mistakes... If you try it, at least you tried it, and then you see very often it works or didn't work out." This participant states that one thing they learned from the FOLC (and not from the NFW) is that you should commit to trying a teaching technique for at least one semester in order to get adequate information to decide if you should continue with the change or not. This participant acknowledges that they may make mistakes in implementing a new teaching technique, but that should not stop them from trying, or from persisting with the change once they have made it. This was a lesson they learned from the FOLC. Similarly, another participant admitted, "For me I is hard to implement some of the new engagement techniques, and I think I would have maybe even given up without being able to get some feedback and learn how to implement things better and kind of just keep up with it." For this member, getting feedback from the FOLC helped them persist in trying new teaching techniques.

Some of our participants shared the specific teaching strategies they implemented because of the FOLC. For example one member shared that the FOLC, "encouraged me to actually jump into the more engaged teaching techniques, you know, trying them out in class. I made a lot of use of whiteboards after getting some help and got some good tips on that from some of my online [FOLC] colleagues...We had a group that could all kind of talk and say if something was going well or not, you know, 'I was trying the whiteboards and couldn't cut them right, how did

TABLE V. Impacts of participation in the NFW-FOLC. People could fall into more than one category. Count represents the number of participants coded to a category. Percentages are out of 34 participants.

\begin{tabular}{lccccccc}
\hline \hline Code & $\begin{array}{c}\text { Implementation } \\
\text { change }\end{array}$ & $\begin{array}{c}\text { Increased } \\
\text { reflection }\end{array}$ & $\begin{array}{c}\text { Gained } \\
\text { confidence }\end{array}$ & $\begin{array}{c}\text { Gained } \\
\text { knowledge }\end{array}$ & $\begin{array}{c}\text { Students } \\
\text { benefited }\end{array}$ & Saved time & Resource \\
\hline Count & 28 & 18 & 10 & 34 & 7 & 5 & 31 \\
Percent & $82 \%$ & $53 \%$ & $29 \%$ & $100 \%$ & $21 \%$ & $15 \%$ & $91 \%$ \\
\hline \hline
\end{tabular}


you manage to do that?" This FOLC member attributes their frequent use of the whiteboard technique $[55,56]$ in their classes to the encouragement and implementation assistance from their cohort.

The SoTL projects FOLC members were asked to complete were another source of motivation for our participants to try a new teaching technique. As one of our members explained, "What I did [for my project] was I tried out oral exams in my junior/senior level quantum mechanics class which I definitely think that I wouldn't have done if I wasn't in the FOLC. I had this idea and I thought it sounded really cool. [The facilitator] talked a lot about his oral exams and things like that, so I thought 'oh, I want to try it, '... but I probably would've just given up and said 'oh well I wanted to do this thing but it's too scary so I'm not going to do it.' But because I had the FOLC and I had said this is what I want to do, and I had other people who said 'oh that sounds really, really cool, we really want to hear how it's going to turn out, and here's some ideas for implementing it,' that made it happen." The cohort's encouragement and helpful ideas motivated this participant to implement a new assessment strategy that they thought was "really cool" but also intimidating to put into practice. The FOLC helped this participant push past their trepidation and implement the new technique.

We also heard some of our participants describe plans to try materials and methods they learned about in the FOLC. One member shared, "Next semester I already have things that other people [in the FOLC] have done and used that I plan on implementing. For example, I know [the Facilitator] does like a one minute 'what did you learn, what's still confusing,' and I'm going to start doing that next semester." Here we see one member describing teaching strategies, learned from their fellow cohort members, that they plan on implementing during their next term of teaching. This excerpt shows that the FOLC has the strong potential to affect the teaching of its members even after they have completed the year-long program.

A number of the FOLC members had tested out an RBIS in some form before attending the NFW. The success of those initial attempts varied and some of our participants talked about how the FOLC helped them modify (and improve) their implementation of that previously tested strategy. For example, one participant shared, "Before [the FOLC] I just gave the clicker questions and then moved on, but based on feedback from the FOLC I now use the clickers mainly for peer instruction where they have to try something on their own to begin with and then spend one or two minutes talking with their peers and trying to come up with solutions. So based on that, I've noticed that the students are less likely to fall asleep and seem to be more invested in the learning process." This participant learned from their cohort how to implement clicker questions more effectively and they have seen signs from their students that these changes are working. The FOLC has helped its members implement RBISs with more success.

\section{Increased reflection}

Over half of our members reported the FOLC caused them to reflect on their teaching practices, what goes on in their classroom, and how to assess changes they have made. One of our members shared that the best and worst activity described in Sec. III, "helped me kind of take a moment and reflect on 'oh yeah, I did do that pretty well,' or 'yeah, that really sucked, let's talk again." 'The FOLC meetings helped this participant pause and process how their teaching was going. In this reflection time, the participant could both celebrate their successes and identify areas that needed improvement.

Another participant shared that their involvement in the FOLC has caused, "a reflection of what can I do better in, what things am I doing well, and seeing how other people have answered those questions and what are the questions that I should be asking myself." As described in the excerpt in the above paragraph, this participant too reports that the FOLC helped them consider their teaching strengths and weaknesses. Further, they have learned other questions they can be reflecting on. Being part of a cohort has also helped this participant develop their reflecting skills because they have seen how their cohort members tackle the abovementioned questions. This is exactly the kind of thinking we want to encourage our members to engage in.

Lastly, a number of our participants talked about how the SoTL projects affected their thinking about teaching. As one cohort member explained, "I think everyone did try new things and were introduced to the idea of thinking about how to evaluate effectiveness. I think that on those fronts it was effective in getting us to try at least one thing that was new, and to think deeply about how to evaluate success, what does success mean. So that was good. I think that's a good skill for all of us to be able to use going forward." Through the SoTL projects, participants learned how to evaluate things they try in their classroom and to consider the profoundly important question, "what does success mean?" in the context of their classroom and the method they tried. As this participant notes, this reflective skill is one they can use in the future.

\section{Increased confidence}

Nearly one-third of participants said the FOLC increased their confidence in some aspect of teaching (e.g., gauging student learning; trying a new teaching strategy). One participant said that the FOLC has, "made me more confident about pushing through some of the changes I was trying to make...I tried to incorporate the small whiteboards as discussion starters. I think hearing about the whiteboards that a couple of other people were having trouble trying to figure...made me feel a little bit better about the fact that it wasn't going quite as planned." 
The FOLC gave this participant the confidence to follow through with a new technique even though it was not going perfectly. This same participant went on to describe, "we're about to start a new quarter at the end of the month, so now I'm building a syllabus for two different classes, and I guess I feel more confident putting things into that I might not have otherwise because I know I can go back to folks and say 'okay, I'm trying to do this, tried it in the first lecture and it didn't work, what do you suggest?'... [The FOLC] gives me support that I might not have otherwise to sort of stay with it and figure it out." With the FOLC community behind them, this member felt confident trying new techniques in their classes. The member also says the FOLC helps them have the confidence to persist in the changes they make.

\section{Knowledge}

All of our FOLC members discussed learning something from the FOLC experience. Three themes appeared in the types of knowledge they described learning: teaching knowledge, professional knowledge, and awareness they were not alone in the challenges they faced as new faculty members. Table VI shows the number of participants who fell into each category. Participants often fell into multiple categories.

Teaching knowledge.-Almost everyone reported gaining knowledge about teaching. This knowledge came in the form of implementation help, sharing of resources, reinforcing material introduced at the NFW, learning how to evaluate their teaching, and/or learning about more teaching techniques. For example, one participant stated, "I think the one [meeting] topic I found really informative for me was the writing exam questions thing that we did...I felt like there was a lot of discussion about cooperative group problem solving and context rich problems and conceptual questions and that sort of day to day stuff, but when it came down to it I feel like a lot of us still had no idea how to write a good exam problem or how to write exams. That really helped me reevaluate things a lot. I think it was helpful because I hadn't really discussed it." The FOLC helped this member learn how to better evaluate their students through well-constructed exams. This was a self-reported gap in the member's knowledge that the FOLC helped fill.

TABLE VI. The subcodes of the impact "gained knowledge." People could fall into more than one category. Count represents the number of participants coded to a category. Percentages are out of 34 participants.

\begin{tabular}{lccc}
\hline \hline Subcode & $\begin{array}{c}\text { Teaching } \\
\text { knowledge }\end{array}$ & $\begin{array}{c}\text { Professional } \\
\text { knowledge }\end{array}$ & $\begin{array}{c}\text { Awareness they } \\
\text { are not alone }\end{array}$ \\
\hline Count & 32 & 11 & 19 \\
Percent & $94 \%$ & $32 \%$ & $56 \%$ \\
\hline \hline
\end{tabular}

Other members talked about how they were able to learn more about a technique they were trying to implement. One member shared, "I mean having people come in and talk about implementation after we'd had a chance to screw it up was also helpful, because then it's a lot easier to know what questions you should be asking, what problems you're going to have once you've already had the problems. I had some people coming in and talking about whiteboards halfway through this last semester, and I already knew that some things weren't working exactly how I wanted them to, and then I got some ideas as to where to go." This member had been introduced to the whiteboard technique at the NFW and was trying it out during their time in the FOLC. They were able to ask specific implementation questions to guest speakers that came to one cohort meeting. In this way, the FOLC extended the knowledge they learned at the NFW. If one thinks of the NFW as an introductory survey course, then the FOLC meetings, especially when there are guest speakers, can be thought of as more advanced seminars on specific topics.

We also included instances of the FOLC helping participants retain the knowledge learned at the NFW in the teaching knowledge category. As one participant described, "One of the things that I thought was helpful [about the FOLC] was that all these different teaching methods that I learned about at the New Faculty, Physics Faculty Workshop, it helps just hearing other people talk about them, it helped me remember them, such as just-intime teaching and collaborative learning and all these little ways of teaching. It just kind of helped enforce and strengthen what I got from the New Physics Faculty Workshop." The FOLC helped some participants deepen their awareness and knowledge about teaching techniques through repeated exposure to the ideas.

Professional knowledge.-Around one-third of interviewed participants reported learning professional knowledge: what other institutions are like and how they function. Lessons in "how to be a faculty member" also fall into this category of knowledge. Essentially, professional knowledge gave participants context such that they could compare their teaching situations to others'. One member said about their FOLC experience, "I'm finding that it's really useful to see the spectrum of how things get done, like even when there's a challenge then other people are like 'oh yeah, our department's crappy about that too.' It's still kind of nice to see okay here's how it looks in several other different departments so if my department does it this way then we're not crazy, or hey, somebody's got a really good idea for that. You know, you do your undergrad at one place and you do your PhD at another place and maybe you do your post-doc at a third place, but that's not really a big sample size...So seeing a range of what is normal in other departments helps me orient, especially when I feel 
like I'm in new territory...Being able to get a sense of how it works in other places feels like a way for me to learn a bit more about the job without having to take as many risks in my department." This participant is describing a unique affordance of the FOLC because it connects people from different institutions, allowing participants to gain perspectives from outside their local context. This is perhaps especially important for new faculty who, as this FOLC member notes, have limited experience with different institution types. The FOLC helped members learn about how different physics departments function and that knowledge could help some of them navigate decisions in their home department.

Some members also cited this contextual knowledge as useful for potential future career decisions. As one participant put it, "I think I'm going to be a little more cognizant of the type of institutions that are out there when I deal with people, and if I apply to another job at some point I think that's going to be helpful there." This participant observed the varying teaching loads and resources their fellow cohort members had at their respective institutions. They predicted that this information would be useful if they consider moving jobs at some point.

Awareness they are not alone.-Over half of the interviewed participants reported learning that they were "not alone" in their teaching challenges. These participants talked about learning through the FOLC that everyone experiences similar issues and has common struggles, no matter who your students are. One member said, "I mean the thing that really strikes me is that everybody seems to be having the same problem and the same concerns that I have." This sentiment was echoed by another participant who said of their FOLC experience, "I learned a lot. A big part of it was just learning that the problems I deal with are the same problems everybody else has. It was comforting to know that everyone's struggling with the same kinds of problems." These FOLC participants saw that other young faculty don't know all the answers either. There was comfort in the shared challenges and concerns. We expect this knowledge to help our participants persist in the teaching changes they try, even if they encounter difficulties, because they now know that struggles are common (and can be overcome).

This is an important finding. Unlike the other impacts which we specifically designed the FOLC to achieve, we did not start the FOLC expecting "learning you are not alone" to be an outcome. And yet, half of our participants reported this outcome. The frequency with which participants reported this to be a significant impact points to both a barrier to reform (faculty blame themselves instead of understanding the difficulty of the task at hand) and the importance of community for sustained and productive faculty development. It is only through participation in a community in which vulnerability is safe that this lesson could be learned. It is a valuable contribution to faculty development that is uniquely afforded by the FOLC model.

\section{Benefiting students}

One-fifth of our interviewed members specifically mentioned how their participation in the FOLC benefited their students. They reported students saying an activity or teaching strategy they tried helped them. For example, one faculty member said that their SoTL project on peer evaluation of labs, which they completed in collaboration with fellow cohort members, benefited their students. They described that their students, "were able to write up their lab reports and then send them off cross country electronically to be reviewed by their peers [another cohort member's students] and get some feedback. The goal was that this would improve their writing...I thought it was a good activity and that students appreciated getting feedback from someone besides me, and I think they maybe took it to heart a little bit more, because they kept hearing the same comments from me over and over and after hearing them from someone else it's like 'oh maybe this really is important." This member's SoTL project allowed their students to write for a new audience and get outside feedback on their work. The participant reported that they thought their students valued this opportunity. In this way, their participation in the FOLC had a direct benefit for their students. Recall, the overarching goal of the NFW-FOLC project is to improve students' educational experiences in physics and astronomy. (Note, too, we are reporting here on the fraction of participants who spontaneously reported this impact, but we expect if we had explicitly asked our participants about the impact of the FOLC on their students, we would get a higher percentage saying their students benefited).

\section{Saving time}

Fifteen percent of the FOLC members described the FOLC as helping them save time and be more efficient in improving their teaching. For example, one member described a meeting where, "we had, again, a few, three or four, guest speakers, and they talked about their experiences, and they talked about what they're using in their classrooms...that was a little bit like a crash course on how to do many things. It was like skimming a book on teaching." A panel of guest speakers helped this member learn a lot of useful teaching tips during the time span of one, ninety-minute meeting. For another FOLC member the community gave them, "some new things to try that I wouldn't have thought of by myself, knowing some pitfalls in advance, knowing some other things in advance, that otherwise would take me a year or two to figure out." The FOLC not only provided this participant with teaching ideas to try, but also alerted them to implementation challenges they may face. The FOLC made them aware of these "pitfalls" before they even tried the technique and 
that saved them the time of having to figure it out themselves.

This is a very important finding and one that while we hoped for, was an open question for us at the beginning of the project. Participating in the FOLC takes time for very busy new faculty. It was a concern for us, and has been brought up by others as a potential negative aspect of the FOLC model, that participation requires time from already overwhelmed faculty. Not only did we not see faculty complain about the time spent (nearly all reported the time to be valuable) but we see reports of faculty claiming participation was actually a time saver. This is a very encouraging result for the FOLC model of professional development.

\section{Gaining resources}

Over $90 \%$ of FOLC participants talked about gaining some (nonmaterial) resource because they were part of the FOLC. There were a range of responses that fell into this code; often these resources were forms of interpersonal relationships and support. Below we elaborate on some of the most common types of resources mentioned: community of support, accountability, and access to experts.

Many of these resource impacts had to do with interacting with people in the FOLC and having a community of support. In describing how they used the asynchronous platform one participant shared, "I think I posted when things were not going great for me, like within my department, and I kind of needed to vent a little bit, and just to get the emotional support." For this participant, their FOLC cohort provided needed moral support. Similarly, another participant said they would recommend the FOLC to other NFW participants because, "The [NF] workshop itself was great but because it was like a firehose it's very easy to go back to your institution and just not work on stuff. Having a little bit of continued accountability and community to talk about these things was really helpful. It helps you implement some of this... And also just having other people at the same career stage who you could freak out with...it's very important to freak out with fellow people." This FOLC member valued their cohort because they were a group to "freak out" with about the challenges of being a new faculty member, and in addition to that moral support they could get concrete implementation advice. In this excerpt we also see another theme from the resource impacts: that of accountability. The FOLC helped this member (and others) actually follow through on changes the NFW motivated them to want to try. The NFW can be overwhelming in the amount of information presented over just a couple of days, and the FOLC helped this participant act on the information rather than become paralyzed in all the options.

In stating what was the most helpful part of the FOLC one member answered, "I think talking to my peers is probably the most useful. But as I said before, I think sometimes learning, even if it's just small advice from people with more experience [guest speakers], that's useful too." This is another example of the community being a resource for our participants. In particular, a community of peers was helpful for this participant. The value of a peer group was expressed by a number of FOLC members when describing their appreciation for their FOLC cohort. In this excerpt we also see the FOLC member talking about how they found the more experienced guest speakers useful too. This was another resource expressed by multiple FOLC members: having access to more experienced practitioners and teaching experts. A different FOLC member said that one of the reasons the FOLC was worthwhile to them was because, "I can learn from the experts that I don't think I can have any opportunity by myself to get in touch with them. I think this kind of connection is definitely valuable." The FOLC helped participants connect with experienced practitioners of the teaching techniques they were trying out. This is a resource of being a FOLC member because part of the design of the NFW-FOLC includes bringing in guest speakers.

While it is perhaps unsurprising that FOLC members gained these resources as we designed the FOLC to provide them, the fact that most of our members cited benefitting from some FOLC resource supports our NFW-FOLC design. For example, participants talking about how they valued the peer group of their cohort supports our design principle 6: Foster a supportive community, and shows success in implementing this part of our design.

\section{B. Discussion of self-reported impacts of the NFW-FOLC}

\section{Outcomes consistent with learning objectives}

Above we have presented the major themes that emerged from participants' statements about the impact of being a member of the NFW-FOLC. We now consider how these impacts provide evidence that we are meeting our stated learning objectives for participants and the ways these impacts are uniquely supported by the FOLC model of professional development. Table VII shows the connections between our learning objectives and the reported impacts of the NFW-FOLC.

Below we discuss each of our six learning objectives in the context of reported impacts and unique affordances of a virtual community.

1. Develop reflective teaching habits and a dedication to continuous teaching improvement. We assert we are meeting this objective. We also assert that the FOLC model helps achieves this goal more robustly than traditional change efforts.

Many participants talked about the FOLC increasing their reflection on their teaching. They reported the SoTL projects helped them think about their teaching goals and how they can assess their 
TABLE VII. Connections between NFW-FOLC learning objectives and the reported impacts of participating in the FOLC.

\begin{tabular}{|c|c|}
\hline Learning objective & $\begin{array}{l}\text { Reported FOLC impacts associated } \\
\text { with learning objectives }\end{array}$ \\
\hline $\begin{array}{l}\text { Develop reflective teaching habits and a dedication to } \\
\text { continuous improvement of teaching. }\end{array}$ & $\begin{array}{l}\text { - Increasing reflection } \\
\text { - Gaining confidence } \\
\text { - Gaining awareness that you are not alone }\end{array}$ \\
\hline Increase knowledge and awareness of RBISs. & $\begin{array}{l}\text { - Gaining teaching knowledge } \\
\text { - Gaining resource of the FOLC: Access to teaching experts }\end{array}$ \\
\hline Maintain or increase motivation to implement RBISs. & $\begin{array}{l}\text { - Gaining confidence } \\
\text { - Implementation change } \\
\text { - Gaining resource of the FOLC: Accountability }\end{array}$ \\
\hline $\begin{array}{l}\text { Implement RBISs consistent with recommendations from } \\
\text { research. }\end{array}$ & $\begin{array}{l}\text { - Gaining teaching knowledge } \\
\text { - Implementation change } \\
\text { - Increasing reflection } \\
\text { - Gaining resource of the FOLC: Access to teaching experts }\end{array}$ \\
\hline Persist in implementation of RBISs. & $\begin{array}{l}\text { - Implementation change } \\
\text { - Gaining confidence } \\
\text { - Gaining awareness that you are not alone } \\
\text { - Gaining resource of the FOLC: Accountability }\end{array}$ \\
\hline $\begin{array}{l}\text { Increase sense of empowerment regarding themselves as } \\
\text { teachers (includes confidence using RBISs). }\end{array}$ & $\begin{array}{l}\text { - Gaining confidence } \\
\text { - Gaining awareness that you are not alone } \\
\text { - Increasing reflection }\end{array}$ \\
\hline
\end{tabular}

teaching. In addition to their direct self-reports of becoming more reflective about teaching, we observe them reflecting throughout their experience during their virtual meetings and on the asynchronous communication board. It would be expected that engaging in regular reflection would increase reflectiveness in general, as supported by their selfreports. The FOLC also increased participants' confidence in their teaching skills and showed them that they are not alone in the teaching challenges they face; we expect this confidence and knowledge improves their dedication to continuous teaching improvement because they feel more comfortable trying new techniques and persisting with them even when difficulties arise. Indeed, learning that one's teaching struggles are common, and seeing how other people overcome these issues, promotes a growth mindset around teaching.

The evidence we see that participants are increasing their reflectiveness around teaching comes from reports of activities that are specific to the community of the FOLC. It is through their interactions with others as they learn and share, and as they share their SoTL projects, that they are reporting increased levels of reflection and are indicating a dedication to continuous teaching improvement. This appears to be an affordance specific to the FOLC model.

2. Increase knowledge and awareness of RBISs. We assert that we are meeting this objective and the FOLC model achieves this goal more robustly than traditional change efforts.
Almost all of the interviewed participants talked about gaining teaching knowledge as an outcome of their FOLC experience. Participants talked about gaining this knowledge both from other members of the cohort and from the expert guest speakers. While traditional dissemination methods are also good at increasing knowledge and awareness, the FOLC model offers several clear advantages. First, it allows for an extended learning experience where more knowledge can be gained due to the extra exposure. More importantly, the structure of the FOLC allows the participants to have a say in what knowledge they learn. (In our instantiation of the FOLC model, participants request topics for guest speakers who are selected based on expressed interest). This means the knowledge gained in the FOLC is more likely to be directly applicable to the participants' needs. Indeed, participants have the chance to gain more knowledge about a teaching technique as they are implementing it for the first time. Finally, they have the opportunity to also learn from each other which affords the acquisition of practical, on-the-ground knowledge that is harder to acquire in traditional D\&D model efforts.

3. Maintain or increase motivation to implement RBISs. We assert that we are meeting this objective and the FOLC model achieves this goal more robustly than traditional change efforts.

Most participants reported actually implementing (or refining) an RBIS as a result of their FOLC experience. The FOLC is motivating implementation 
of RBISs. Participants' reports show us not only that they were motivated by the FOLC but also the mechanisms of this motivation. For example, a sizable portion of participants reported the FOLC gave them confidence to try a new teaching technique. Other members reported being motivated to try a teaching technique after seeing a fellow cohort member try the technique. Some FOLC participants talked about how the accountability they felt to their cohort motivated them to try a RBIS. Importantly, none of the interviewed FOLC members reported that the FOLC decreased their motivation to try a RBIS.

It is of note that the ways in which participants reported being motivated are focused on unique affordances of the virtual community. It was through their interactions with others and the sense of community they shared that the motivation frequently came. While learning about a teaching innovation can motivate faculty to try it, we see from our FOLC participants that having a community to support, inspire, and hold one accountable increases this motivation.

4. Implement RBISs consistent with recommendations from research. We assert that we are likely meeting this objective and that the FOLC model achieves this goal more robustly than traditional change efforts.

We have not observed the classrooms of these faculty. However, we have indications that our participants are reaching this objective. For example, most of our participants gained teaching knowledge from the FOLC, often in the form of implementation help. Participants spoke of receiving implementation help from both the expert guest speakers and other cohort members. Participants valued the opportunity to ask questions based on the teaching difficulties they were encountering and to get specific help and advice. They spoke of the way this impacted their teaching. It is reasonable to assume that the implementation troubleshooting that occurs in the FOLC guides members towards productive instantiations of an RBIS. We also had a few of our members describe how the FOLC helped them improve the implementation of an RBIS they had tried prior to attending the NFW. Finally, at least half of our participants increased their reflection on their teaching, and part of this reflecting was considering areas of their teaching which needed improvement. It can be reasonably expected that if implementation of an RBIS was going poorly our participants would identify that in their self-reflection and bring it up with the cohort, leading to better implementation. What we clearly see from the FOLC impacts discussed in our interviews is that participants are trying RBISs in their classroom and are talking about their efforts with their cohort, eliciting advice and resources for their implementation along the way. The cohort has access to experienced practitioners and facilitators who can guide participants towards implementation consistent with recommendations from the research.

Again, the FOLC model affords unique opportunities to meet the objective of implementing methods consistent with recommendations from research. Participants speak of the ways in which their implementation was impacted by opportunities to troubleshoot with both the group and with experts. They reported making changes in their implementation (not just in trying new things) as a result of the FOLC experience and specifically the interactions they had with the community, which are absent from traditional dissemination efforts.

5. Persist in implementation of RBISs. We assert we are meeting this objective in the short term and likely meeting it in the long term. We also assert that the FOLC model achieves this goal more robustly than traditional change efforts.

A few FOLC members specifically talked about how the advice and knowledge they gained from the FOLC helped them persist with a teaching change, even when challenges were encountered. Others reported the FOLC gave them confidence to stick with a new teaching technique they might otherwise have abandoned. Participants reported learning through the FOLC that the teaching challenges they face are common. The knowledge that they were not alone in their struggles in the classroom was comforting for members, and likely helped them keep going with their teaching changes. Some members also reported that they felt their cohort kept them accountable to follow through with the teaching changes they wanted to make. The community of the cohort is helping members persist with their teaching changes through the FOLC experience. We are in the process of collecting and analyzing longitudinal data to determine if the changes inspired by the FOLC persist over the years (initial data suggests yes).

Again, the increase in persistence can be directly traced to affordances of the FOLC that are not present in traditional dissemination efforts. When participants spoke of persisting through difficulties they may otherwise have not, they talked about the impacts of the community. It was their engagement with others that helped them meet challenges and supported them emotionally as they navigated difficulties.

6. Increase sense of empowerment as teachers. We assert we are meeting this objective. We also assert that the FOLC model achieves this goal more robustly than traditional change efforts. 
Many participants described the FOLC increasing their confidence as teachers. It also showed them that they were not the only one struggling with a certain teaching technique or teaching difficulty. This knowledge can be empowering because it can stop faculty from thinking their teaching challenges are due to an individual flaw which can never be overcome. Additionally, because the FOLC encouraged members to reflect on what was going well in their classroom and what needed to be improved, it helped them slow down and acknowledge their successes. These can often be overlooked as people have a tendency to focus more on challenges than successes [57]. Acknowledging one's successes is empowering rather than demoralizing.

Again, the FOLC model offers unique affordances for meeting this objective. It was through the community and their interactions with other cohort members that participants report they gained confidence in their abilities. Helping them understand the inherently difficult nature of implementing RBISs and the ways in which all faculty struggle is essential, but this is challenging to do with other professional development models.

Above we have argued that the impacts reported by the NFW-FOLC participants are uniquely supported by the FOLC model for educational change. Specifically, we have stated that the community aspect of the model helps our participants achieve our learning objectives more strongly than a traditional D\&D model would. Figure 1 shows the connection between the FLC model and the FOLC model. Both FLCs and FOLCs provide some form of community. The FOLC model, however, enhances the benefits of a

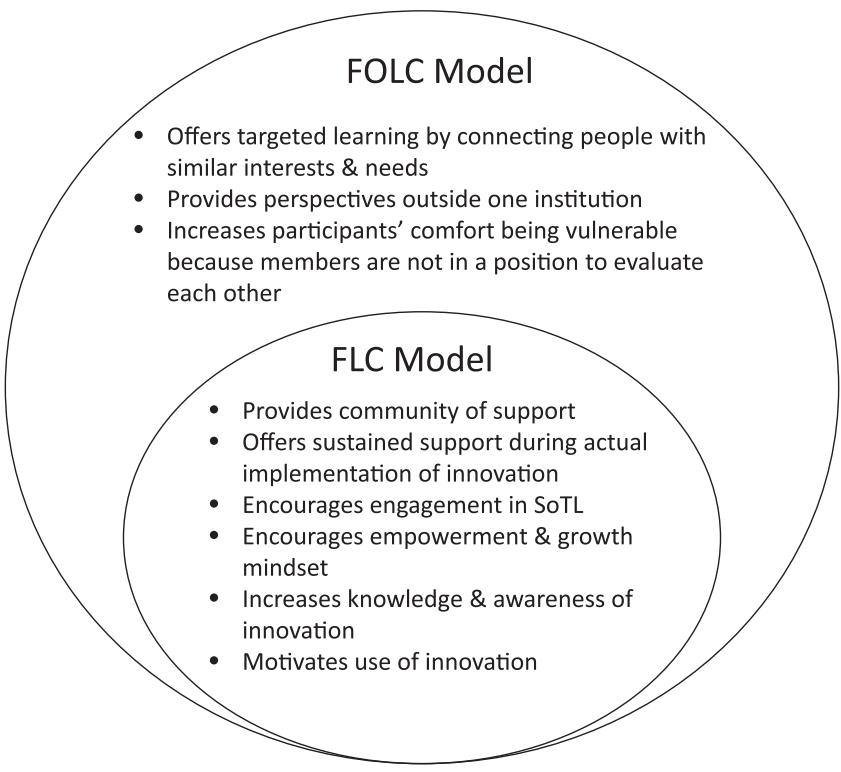

FIG. 1. The benefits of two change models. The FOLC model incorporates the advantages of FLCs while adding further benefits. typical FLC by providing more targeted learning opportunities and connecting people with similar needs regardless of geographic location. Because the population of our FOLC was solely new physics and astronomy faculty, most of the pedagogical knowledge and techniques discussed were developed for teaching physics and astronomy students. All the examples presented and implementation issues discussed were from physics and astronomy classrooms. Thus, the FOLC model is better able to address discipline-specific challenges and needs than the FLC model which mainly connects faculty from many different disciplines. The FOLC model further enhances the benefits of the FLC model by connecting diverse people with similar interests. The members of our NFW-FOLC are diverse in that they come from different institutions, bringing varied perspectives on physics and astronomy teaching. However, the FOLC members are connected by their specific interests in improving physics and astronomy education. This combination of a discipline-specific, yet institutionally diverse population allows for deeper learning than in an FLC. Additionally, as reported by our participants, a community populated from different institutions means participants feel more comfortable being vulnerable about their teaching challenges and they receive targeted teaching advice since they are not being evaluated by fellow community members. This is another important advantage offered by an online faculty community.

\section{Outcomes beyond learning objectives}

Some of the reported impacts of participating in the NFW-FOLC suggest participants are learning things beyond our learning objectives:

1. FOLC participants gained professional knowledge.

We did not explicitly plan that our participants would gain professional knowledge (i.e., knowledge about how things work at other universities, not specific to teaching) from their FOLC cohort yet it turned out to be an important benefit from the participants' point of view. FOLCs connect people from across the country at many different institution types. In talking about their teaching, participants talk about the context in which they are teaching. This gives cohort members a sense for how different departments and institutions function. This is an affordance of the FOLC model, specifically over the in-person FLC model.

2. FOLC participation saved members time.

The other impact that we did not directly plan for, but were hopeful about, was that the experience saved members time. Faculty members have little free time and some people hesitate to join the FOLC because of the time commitment. We therefore find it very encouraging that some of our members said the FOLC actually saved time in their teaching 
development. The structure of the FOLC is not onerous for participants.

The NFW-FOLC learning objectives encompass pedagogical content, attitudinal shifts, and skills development for continual professional growth. From our interview data, we have presented evidence that our FOLC members are growing in all three dimensions. The success of our application of the FOLC model supports the efficacy of the model itself. We also see that the mechanisms by which we are achieving our objectives are directly tied to the community aspects of the FOLC experience and therefore are not easily replaced by traditional dissemination or professional development.

\section{CONCLUSIONS AND FUTURE WORK}

In sum, we have identified a critical problem in the promotion of research-based teaching reforms: Typical approaches for promoting instructional change are not sufficient for bringing about sustained and impactful reforms. We provided an analysis of why the common D\&D model for educational change falls short of these goals and we have presented a FOLC model, an extension of the FLC model and consistent with the Propagation paradigm, to address the shortcomings of traditional reform efforts. This FOLC model of professional development for educational change is designed to meet known challenges in educational transformation primarily through the affordances offered by a community of support. We described an implementation of the FOLC model and showed through analysis of interview data that there is a perceived need for the FOLC model and that participants of the NFW-FOLC are meeting its learning objectives through mechanisms unique to a FOLC experience. These results indicate the efficacy and importance of the FOLC model.

The FOLC model is generalizable beyond the application presented here. The NFW-FOLC is designed for a specific audience (new physics and astronomy faculty). The model, however, can be applied in a number of other ways: a FOLC could be specific to content (i.e., teaching upper level quantum mechanics or advanced lab), or audience (i.e., community college physics faculty), or pedagogy (i.e., flipped classroom), or topic (i.e., integrating metacognition activities). For example, a FOLC is offered for faculty implementing the Next Gen PET curriculum. This FOLC has seen similar positive impacts as we report for the NFW-FOLC [58-60]. This model has been used in other STEM disciplines as well [61].

In looking forward to the use of the FOLC model we note two additional advantages and highlight one challenge for future work. First, the FOLC model, once implemented, is relatively inexpensive. There are numerous technology platforms to support a virtual community which are free or inexpensive and the development of these platforms is rapidly progressing. Even during the short duration of this project we have seen vast improvements in the technology available to support meaningful virtual connections and community engagement. The greatest "cost" to implementing a FOLC is the time of the facilitators. The second advantage we want to highlight is the way the FOLC can support faculty in becoming change agents themselves. As faculty become more expert and confident in their own use of RBISs it is expected that they will be better positioned to impact others in their department (we investigate this more directly in longitudinal interviews). We hypothesize, and are exploring in our ongoing longitudinal interviews, that the entire department may benefit from the FOLC participation of one member. So, while a FOLC may directly involve only a few faculty, indications are the model can have significant impacts across a broader community.

A significant challenge for future work is documenting how to best facilitate a FOLC for engaged and sustained participation and to encourage deep reflection about teaching among participants. In reviewing recordings of virtual meetings and analyzing asynchronous communications it is clear that deliberate attention is needed to ensure the most productive outcomes. We have done some analysis of virtual meetings [62] and asynchronous communications [63] to better understand facilitator moves and structural supports that encourage desired outcomes. Initial analysis indicates that helpful facilitator moves include the facilitator withholding their own opinion to encourage others to share, giving agency by focusing the conversation on ideas of participants, and encouraging participants to elaborate on their ideas. However, more work is needed in this area.

\section{ACKNOWLEDGMENTS}

We thank Stephanie Chasteen (Chasteen Educational Consulting) for contributing the demographic data for the NFW population, which was collected as part of the external evaluation of the workshops. Additionally, Joel Corbo participated in the initial stages of this project and assisted with framing and data collection. We also thank all of the FOLC facilitators: Jeremy Bailin, Jessica Bickel, Zoe Boekelheide, Darsa Donelan, Alexander Kemper, Mary Bridget Kustusch, Gillian Ryan, Adrienne Traxler, Caitlin Williams, Michael Wood, and Jason E. Ybarra. This work was supported by the National Science Foundation (NSF-DUE-143177, NSF-DUE-1431638, and NSF-DUE1431681).

M. D. and A. C. L. contributed equally to this work. 
[1] E. F. Redish, Teaching Physics with the Physics Suite (John Wiley \& Sons, Somerset, NJ, 2003).

[2] C. Henderson, M. Dancy, and M. Niewiadomska-Bugaj, Use of research-based instructional strategies in introductory physics: Where do faculty leave the innovationdecision process?, Phys. Rev. ST Phys. Educ. Res. 8, 020104 (2012).

[3] G. M. Novak, E. T. Patterson, A. D. Gavrin, and W. Christian, Just-in-Time Teaching: Blending Active Learning with Web Technology (Prentice Hall, Upper Saddle River, NJ, 1999).

[4] D. R. Sokoloff and R. K. Thornton, Using interactive lecture demonstrations to create an active learning environment, Phys. Teach. 35, 340 (1997).

[5] R. Beichner, The student-centered activities for large enrollment undergraduate programs (SCALE-UP) project, in Research-based Reform of University Physics, Reviews in PER Vol. 1, edited by E. F. Redish and P. J. Cooney (American Association of Physics Teachers, College Park, MD, 2007).

[6] E. Mazur, Peer Instruction: A User's Manual (Prentice Hall, Upper Saddle River, NJ, 1997).

[7] C. H. Crouch and E. Mazur, Peer Instruction: Ten years of experience and results, Am. J. Phys. 69, 970 (2001).

[8] E. M. Rogers, Diffusion of Innovations, 5th ed. (Free Press, New York, 2003).

[9] C. Henderson and M. H. Dancy, Impact of physics education research on the teaching of introductory quantitative physics in the United States, Phys. Rev. ST Phys. Educ. Res. 5, 020107 (2009).

[10] D. Ebert-May, T. L. Derting, J. Hodder, J. L. Momsen, T. M. Long, and S. E. Jardeleza, What we say is not what we do: Effective evaluation of faculty professional development programs, BioScience 61, 550 (2011).

[11] J. E. Froyd, C. Henderson, R. S. Cole, D. Friedrichsen, R. Khatri, and C. Stanford, From dissemination to propagation: A new paradigm for education developers, Chang. Mag. High. Learn. 49, 35 (2017).

[12] C. Henderson, N. Finkelstein, and A. Beach, Beyond dissemination in college science teaching: An introduction to four core change strategies, J. Coll. Sci. Teach. 39, 18 (2010).

[13] E. Seymour, Tracking the processes of change in US undergraduate education in science, mathematics, engineering, and technology, Sci. Educ. 86, 79 (2002).

[14] R. Khatri, C. Henderson, R. Cole, J. E. Froyd, D. Friedrichsen, and C. Stanford, Designing for sustained adoption: A model of developing educational innovations for successful propagation, Phys. Rev. Phys. Educ. Res. 12, 010112 (2016).

[15] C. Henderson, A. Beach, and N. Finkelstein, Facilitating change in undergraduate STEM instructional practices: An analytic review of the literature, J. Res. Sci. Teach. 48, 952 (2011).

[16] R. Graham, Achieving Excellence in Engineering Education: The Ingredients of Successful Change (Royal Academy of Engineering, London, 2012).

[17] C. D'Avanzo, Postvision and change: Do we know how to change?, CBE Life Sci. Educ. 12, 373 (2013).
[18] M. Borrego and C. Henderson, Increasing the use of evidence-based teaching in STEM higher education: A comparison of eight change strategies, J. Eng. Educ. 103, 220 (2014).

[19] C. Stanford, R. Cole, J. Froyd, C. Henderson, D. Friedrichsen, and R. Khatri, Analysis of propagation plans in NSF-funded education development projects, J. Sci. Educ. Technol. 26, 418 (2017).

[20] C. Henderson and M. H. Dancy, Barriers to the use of research-based instructional strategies: The influence of both individual and situational characteristics, Phys. Rev. ST Phys. Educ. Res. 3, 020102 (2007).

[21] C. S. Dweck, Mindset: The New Psychology of Success, 1st ed. (Random House, New York, 2006).

[22] C. Henderson, R. Cole, J. Froyd, D. G. Friedrichsen, R. Khatri, and C. Stanford, Designing Educational Innovations for Sustained Adoption: A How-to Guide for Education Developers Who Want to Increase the Impact of Their Work (Increase the Impact, Kalamazoo, MI, 2015).

[23] E. Wenger, Communities of Practice: Learning, Meaning, and Identity (Cambridge University Press, Cambridge, England, 1998).

[24] V. Farnsworth, I. Kleanthous, and E. Wenger-Trayner, Communities of practice as a social theory of learning: A conversation with Etienne Wenger, Br. J. Educ. Stud. 64, 139 (2016).

[25] E. Wenger, Communities of practice and social learning systems, Organization 7, 225 (2000).

[26] E. W. Close, J. Conn, and H. G. Close, Becoming physics people: Development of integrated physics identity through the learning assistant experience, Phys. Rev. Phys. Educ. Res. 12, 010109 (2016).

[27] J. Lave and E. Wenger, Situated Learning: Legitimate Peripheral Participation (Cambridge University Press, New York, 1991).

[28] M. D. Cox, Introduction to faculty learning communities, New Dir. Teach. Learn. 2004, 5 (2004).

[29] J. Emerson and F. Mosteller, Development programs for college faculty: Preparing for the twenty-first century, Educ. Media Technol. Yearb. 25, 26 (2000).

[30] D. Sawada, M. D. Piburn, E. Judson, J. Turley, K. Falconer, R. Benford, and I. Bloom, Measuring reform practices in science and mathematics classrooms: The reformed teaching observation protocol, School Sci. Math. 102, 245 (2002).

[31] M. D. Cox, Four Positions of Leadership in Planning, Implementing, and Sustaining Faculty Learning Community Programs, New Dir. Teach. Learn. 2016, 85 (2016).

[32] K. V. Thompson, G. Marbach-Ad, L. Egan, and A. C. Smith, Faculty learning communities: A professional development model that fosters individual, departmental and institutional impact, in Transform. Institutions Undergrad. STEM Educ. 21st Century, edited by G. C. Weaver, W. D. Burgess, A. L. Childress, and L. Slakey (Purdue University Press, West Lafayette, IN, 2016), pp. 312-324.

[33] A. L. Beach and M. D. Cox, The impact of faculty learning communities on teaching and learning, Learn. Communities J. 1, 7 (2009). 
[34] T. L. Tinnell, P. A. S. Ralston, T. R. Tretter, and M. E. Mills, Sustaining pedagogical change via faculty learning community, Int. J. STEM Educ. 6, 16 (2019).

[35] A. Furco and B. E. Moely, Using learning communities to build faculty support for pedagogical innovation: A multicampus study, J. Higher Educ. 83, 128 (2012).

[36] Building Faculty Learning Communities, no. 97, edited by M. D. Cox and L. Richlin (Jossey-Bass, San Francisco, 2004).

[37] J. C. Turner, A. Christensen, H. Z. Kackar-Cam, S. M. Fulmer, and M. Trucano, The development of professional learning communities and their teacher leaders: An activity systems analysis, J. Learn. Sci. 27, 49 (2018).

[38] L. Stoll, R. Bolam, A. McMahon, M. Wallace, and S. Thomas, Professional learning communities: A review of the literature, J. Educ. Chang. 7, 221 (2006).

[39] V. Vescio, D. Ross, and A. Adams, A review of research on the impact of professional learning communities on teaching practice and student learning, Teach. Teach. Educ. 24, 80 (2008).

[40] J. A. Wenner and T. Campbell, The theoretical and empirical basis of teacher leadership, Rev. Educ. Res. 87, 134 (2017).

[41] M. Fullan, The NEW Meaning of Educational Change, 5th ed. (Teachers College Press, New York, 2016).

[42] Workshop for new physics, and astronomy faculty, http://www.aapt.org/Conferences/newfaculty/nfw.cfm (2019).

[43] E. L. Boyer, Scholarship Reconsidered: Priorities of the Professoriate (Carnegie Foundation for the Advancement of Teaching, Princeton, NJ, 1990).

[44] L. Richlin and M. D. Cox, Developing scholarly teaching and the scholarship of teaching and learning through faculty learning communities, New Dir. Teach. Learn. 2004, 127 (2004).

[45] N. F. Dana and D. Yendol-Hoppey, The Reflective Educator's Guide to Professional Development: Coaching Inquiry-Oriented Learning Communities (Corwin Press, Thousand Oaks, CA, 2008).

[46] R. J. Garmston and B. M. Wellman, The Adaptive School: A Sourcebook for Developing Collaborative Groups, 3rd ed. (Rowman \& Littlefield, MD, 2016).

[47] Scholarship Revisited: Perspectives on the Scholarship of Teaching, edited by C. Kreber (Jossey-Bass, San Francisco, 2001).

[48] J. A. Maxwell, Qualitative Research Design: An Interactive Approach, 3rd ed. (Sage Publications, Thousand Oaks, CA, 2013).

[49] M. B. Miles, A. M. Huberman, and J. Saldaña, Qualitative Data Analysis: A Methods Sourcebook, 3rd ed. (SAGE Publications, Thousand Oaks, CA, 2014).

[50] R. Ivie, S. White, A. Garrett, and G. Anderson, Women among physics \& astronomy faculty: Results from the 2010 survey of physics degree-granting departments, https://www.aip.org/statistics/reports/womenamong-physics-astronomy-faculty (2013).

[51] AIP, Physics trends: Women among physics faculty members, https://www.aip.org/statistics/physics-trends/womenamong-physics-faculty-members-0 (2015).

[52] A. Statham, L. Richardson, and J. A. Cook, Gender and University Teaching: A Negotiated Difference (State University of New York Press, Albany, 1991).

[53] S. Chasteen and R. Chattergoon, Evaluation Reports of the New Faculty Workshop (to be published).

[54] M. Dancy and C. Henderson, Pedagogical practices and instructional change of physics faculty, Am. J. Phys. 78, 1056 (2010).

[55] D. MacIsaac, Whiteboarding in the classroom, http:// physicsed.buffalostate.edu/AZTEC/BP_WB/ (2019).

[56] Paradigms in Physics Group, Small whiteboard questions, http://physics.oregonstate.edu/portfolioswiki/strategy: smallwhiteboard:start (2011).

[57] S. Davidai and T. Gilovich, The headwinds/tailwinds asymmetry: An availability bias in assessments of barriers and blessings, J. Pers. Soc. Psychol. 111, 835 (2016).

[58] E. Price, A. C. Lau, C. Turpen, F. Goldberg, M. Dancy, and A. Corrales, Next Generation Physical Science and Everyday Thinking FOLC (to be published).

[59] C. Turpen, F. Goldberg, A. Corrales, and E. Price, Confusion and representational practices as factors that sustain rich pedagogical discussions within faculty online learning communities, in Proceedings of the 2018 Physics Education Research Conference, Washington, DC (AIP, New York, 2018).

[60] A. Corrales, F. Goldberg, C. Turpen, and E. Price, Conversational norms in faculty communities enable and constrain opportunities to learn, in Proceedings of the 2018 Physics Education Research Conference, Washington, DC (AIP, New York, 2018).

[61] K. N. Pelletreau, J. K. Knight, P. P. Lemons, J. S. McCourt, J. E. Merrill, R. H. Nehm, L. B. Prevost, M. Urban-Lurain, and M. K. Smith, A faculty professional development model that improves student learning, encourages activelearning instructional practices, and works for faculty at multiple institutions, CBE Life Sci. Educ. 17, es5 (2018).

[62] A. C. Lau, M. H. Dancy, C. Henderson, and A. Rundquist, Describing and facilitating productive teaching talk in a faculty online learning community, in Proceedings of the 2018 Physics Education Research Conference, Washington, DC (AIP, New York, 2018).

[63] J. C. Corbo, A. Rundquist, C. R. Henderson, and M. H. Dancy, Using asynchronous communication to support virtual faculty learning communities, in Proceedings of the 2016 Physics Education Research Conference, Sacramento, CA (AIP, New York, 2016). 